\title{
ДИНАМИКА СНЕЖНОГО ПОКРОВА И ПРОМЕРЗАНИЯ ПОЧВЫ В УСЛОВИЯХ СОВРЕМЕННОГО ИЗМЕНЕНИЯ КЛИМАТА HА ПРИМЕРЕ САРАТОВА
}

\section{Г.Ф. Иванова, Н.Г. Левицкая' ${ }^{1}$ Ю.А. Скляров, О.В. Шаталова}

\author{
Саратовский государственный университет, \\ кафедра метеорологии и климатологии \\ ${ }^{1}$ Научно-исследовательский институт \\ сельского хозяйства Юго-Востока \\ E-mail: sklyarov@sgu.ssu.runnet.ru \\ E-mail: raizer@mail.saratov.ru
}

На основе ежедневных данных исследована динамика высоты снежного покрова и глубины промерзания почвы на метеостанции Саратов ЮВ за период 1976-2005 годов. Рассчитанные уравнения трендов свидетельствуют об уменьшения высоты снежного покрова и глубины промерзания почвы, о смещении дат установления и схода снега на более ранние, а начала промерзания почвы на более поздние сроки.

\section{Dinamic of the Snow Cover and Soil Frozening in Condichions of Modern Climate Chahge at Saratov as Example}

\section{G.F. Ivanova, N.G.Levitckaya, Yu.A. Sklyarov, O.V. Shatalova}

On the base of daily data the dinamic of snow cover height and soil frozening depth on meteorological station Saratov Yu V for 1976-2005 period was examined. The calculated trends equations make it clear that height of snow cover and depth of soil frozening are going down. Also, the dates of snow cover formation and coming off are displaced to more earlier dates, and the beginning of soil frozening - to more late period of time.

\section{Введение}

Снежный покров играет важную роль в функционировании климатической системы. В силу специфических особенностей снега он существенно меняет радиационный и тепловой баланс подстилающей поверхности, предохраняя почву от выхолаживания, а зимующие культуры от вымерзания, аккумулирует зимние осадки, являясь весной одним из основных источников водного питания почвы. Высота снежного покрова является важным показателем при оценке глубины и степени промерзания почвы, нагрузок на крыши зданий, расчетов мелиоративных сооружений, построенных на местном стоке и т.д.

Глубина промерзания почвы имеет самостоятельное практическое значение для многих отраслей народного хозяйства. Она существенно влияет на жизнь зимующих растений, во многом определяет условия стока талых вод и формиро-

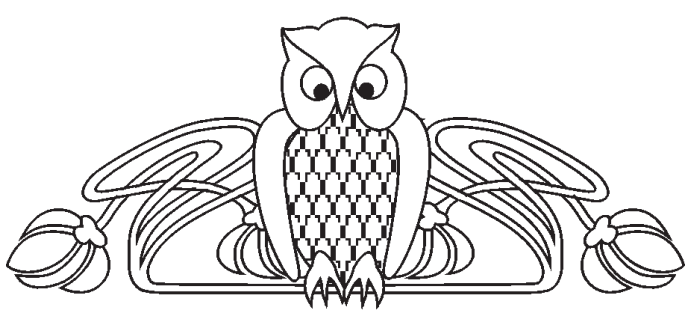

вания водного режима почвы, функционирования подземных коммуникаций.

Целью настоящей работы явилась оценка многолетней тенденции изменения характеристик снежного покрова и глубины промерзания почвы в условиях современного изменения климата на примере Саратова. Исходным материалом для исследований послужили данные наблюдений за высотой снежного покрова по постоянной рейке и глубиной промерзания почвы на метеостанции Саратов Юго-Восток с 1976 по 2005 г.

\section{Снежный покров}

При исследовании динамики характеристик снежного покрова был использован материал ежегодных данных нарастания снежного покрова от декады к декаде, начиная с первой декады ноября и кончая последней декадой апреля.

Анализ этого материала позволил установить календарные даты появления и начала залегания устойчивого снежного покрова, даты начала разрушения и полного схода снежного покрова, декаду наступления максимальной высоты снегового покрова и продолжительность его залегания за последний 30-летний период.

Сравнительная оценка полученных данных с представленными в Научно-прикладном справочнике по климату СССР [1] , где обобщены материалы наблюдений за 1891-1980 гг., показала, что средняя продолжительность устойчивого залегания снежного покрова в условиях Саратова за период 1976-2005 гг. уменьшилась на 4 дня и стала составлять 124 дня (табл. 1). Число дней со снежным покровом за исследуемый период колебалось от 76 (1996-1997 гг.) до 151 дня (1993-1994 гг.). При этом все характеристики динамики снежного покрова свидетельствуют об устойчивой тенденции к их изменению.

Средняя, самая ранняя и самая поздняя даты первого появления временного снежного покрова сместились в сторону более ранних сроков соответственно на 3, 8 и 12 дней.

Средняя дата образования устойчивого снежного покрова переместилась в сторону более ранней на 5 дней и стала приходиться на 30 ноября. Самая ранняя и самая поздняя даты образования снежного покрова в исследуемый период были отмечены 7 ноября 1993 г. и 31 декабря 1982 г. соответственно. Таким образом, самая ранняя 
Характеристика снежного покрова за 1891-1980 гг. и 1976-2005 гг.

\begin{tabular}{|c|c|c|c|}
\hline Показатели & $1891-1980$ гг. & 1976-2005 гг. & Сдвиг дат, дни* \\
\hline Среднее число дней со снежным покровом & 128 & 124 & -4 \\
\hline $\begin{array}{l}\text { Дата появления снежного покрова: } \\
\text { средняя } \\
\text { самая ранняя } \\
\text { самая поздняя }\end{array}$ & $\begin{array}{l}\text { 1.XI } \\
\text { 8.X } \\
\text { 1.XII }\end{array}$ & $\begin{array}{c}28 . \mathrm{X} \\
\text { 30.IX } \\
\text { 19.XI }\end{array}$ & $\begin{array}{c}-3 \\
-8 \\
-12\end{array}$ \\
\hline $\begin{array}{l}\text { Дата образования устойчивого } \\
\text { снежного покрова: } \\
\text { средняя } \\
\text { самая ранняя } \\
\text { самая поздняя }\end{array}$ & $\begin{array}{c}\text { 5.XII } \\
1 . \mathrm{XI} \\
15 . \mathrm{I}\end{array}$ & $\begin{array}{c}\text { 30.XI } \\
\text { 7.XI } \\
\text { 31.XII }\end{array}$ & $\begin{array}{l}-5 \\
+6 \\
-15\end{array}$ \\
\hline $\begin{array}{l}\text { Дата разрушения устойчивого } \\
\text { снежного покрова: } \\
\text { средняя } \\
\text { самая ранняя } \\
\text { самая поздняя }\end{array}$ & $\begin{array}{l}29 . I I I \\
11 . I I I \\
19 . I V\end{array}$ & $\begin{array}{c}11 . \mathrm{III} \\
4 . \mathrm{II} \\
31 . \mathrm{III}\end{array}$ & $\begin{array}{l}-18 \\
-7 \\
-19\end{array}$ \\
\hline $\begin{array}{l}\text { Дата схода снежного покрова: } \\
\text { средняя } \\
\text { самая ранняя } \\
\text { самая поздняя }\end{array}$ & $\begin{array}{c}5 . \mathrm{IV} \\
21 . \mathrm{III} \\
29 . \mathrm{IV}\end{array}$ & $\begin{array}{c}3 . \mathrm{IV} \\
25 . \mathrm{II} \\
27 . \mathrm{IV}\end{array}$ & $\begin{array}{l}-2 \\
-24 \\
-2\end{array}$ \\
\hline
\end{tabular}

* Примечание. Минус означает сдвиг на более ранние, плюс - на более поздние сроки.

дата образования устойчивого снежного покрова сместилась на 6 дней в сторону более поздней, а самая последняя дата наблюдалась на 15 дней раньше, чем в предыдущий период.

Начало разрушения устойчивого снежного покрова стало происходить значительно раньше. Сместились на более ранние сроки по сравнению с климатическими нормами [1] все даты: средняя дата на 18 дней, самая поздняя на 19, а самая ранняя на 7 дней.

Средняя и самая поздняя даты полного схода снежного покрова изменились незначительно (сместились в сторону более ранних сроков всего на 2 дня), а самая ранняя дата схода снежного покрова была отмечена 25 февраля 2002 г., что на 24 дня раньше, чем в предшествующий 90-летний период.

Средняя декадная высота снежного покрова по постоянной рейке в ноябре и декабре практически не изменилась по сравнению с её многолетними средними значениями. В январе, феврале и марте она имеет явную тенденцию к уменьшению и за 30-летний период снизилась в январе-феврале на 6-7 см, а в марте на 4 см (табл. 2).

Таблииа 2

Характеристика высоты снежного покрова, см за декаду по постоянной рейке за 1891-1980 гг. и 1976-2005 гг. (Саратов ЮВ)

\begin{tabular}{|c|c|c|c|c|c|c|c|}
\hline \multirow{2}{*}{ Месяц } & \multirow{2}{*}{$\begin{array}{c}\text { Дека- } \\
\text { да }\end{array}$} & \multicolumn{3}{|c|}{ 1891-1980 гг. } & \multicolumn{3}{|c|}{ 1976-2005 гг. } \\
\hline & & Средняя & Максимальная & Минимальная & Средняя & Максимальная & Минимальная \\
\hline \multirow{3}{*}{ Ноябрь } & 1 & 1 & 6 & 1 &.$^{*}$ & 28 & 1 \\
\hline & 2 & 2 & 16 & 1 & 2 & 37 & 1 \\
\hline & 3 & 5 & 33 & 1 & 5 & 34 & 1 \\
\hline \multirow{3}{*}{ Декабрь } & 1 & 7 & 26 & 1 & 8 & 46 & 1 \\
\hline & 2 & 12 & 46 & 1 & 13 & 46 & 1 \\
\hline & 3 & 17 & 53 & 1 & 16 & 50 & 1 \\
\hline \multirow{3}{*}{ Январь } & 1 & 25 & 90 & 1 & 21 & 102 & 1 \\
\hline & 2 & 33 & 102 & 3 & 26 & 102 & 1 \\
\hline & 3 & 37 & 100 & 2 & 31 & 102 & 3 \\
\hline \multirow{3}{*}{ Февраль } & 1 & 42 & 97 & 4 & 35 & 92 & 2 \\
\hline & 2 & 44 & 97 & 8 & 36 & 92 & 6 \\
\hline & 3 & 42 & 99 & 1 & 38 & 92 & 2 \\
\hline \multirow{3}{*}{ Март } & 1 & 41 & 101 & 2 & 37 & 91 & 1 \\
\hline & 2 & 40 & 110 & 5 & 34 & 87 & 1 \\
\hline & 3 & 27 & 71 & 5 & 26 & 80 & 1 \\
\hline \multirow{3}{*}{ Апрель } & 1 & & 56 & 1 & 8 & 70 & 1 \\
\hline & 2 & 11 & 46 & 1 & 1 & 55 & 1 \\
\hline & 3 & & 14 & 1 & - & 34 & 1 \\
\hline
\end{tabular}

Примечание. * означает, что устойчивый снежный покров наблюдается менее чем в 50-ти процентах лет. 
Наибольших значений средняя декадная высота снежного покрова за период 1976-2005 гг. стала достигать в третьей декаде февраля, вместо второй декады февраля в предшествующий период. По результатам проведенных исследований максимумы высоты снежного покрова для различных лет могут приходиться на разные декады и тем самым быть отделенными друг от друга неравными промежутками времени.Чтобы выяснить, на какую из декад в среднем приходится большинство максимумов высоты снегового покрова, нами были определены максимумы за каждый год. Затем из них были вычислены средние декады, на которые приходится большинство максимумов за весь период наблюдений. И наконец, была определена устойчивость декады с максимальной высотой снегового покрова.

Таким образом, средний максимум высоты приходится на вторую декаду февраля, а именно на 16 февраля. Величина среднего квадратического отклонения ( $\sigma)$ средней декады максимальной высоты снегового покрова составила 2,7 декады. Это на 0,7 декады больше, чем по данным климатического справочника за период 1891-1980 гг. Это свидетельствует о том, что декада с максимальной высотой снежного покрова в последнее 30-летие стала менее устойчивой по сравнению с началом столетия.

Устойчивость максимума находится в прямой зависимости от климатических особенностей зимы. Чем более однообразна зима в смысле группировки декад, лишенных оттепелей, тем чаще максимум приходится на арифметически среднюю дату. При частой смене «южной» и «северной» зим, с большим и малым количеством оттепелей, максимум снегового покрова может сдвигаться с конца зимы к её началу, до периода глубоких оттепелей, уплотняющих или сгоняющих снег среди зимы.

Оценка динамики характеристик снежного покрова проводилась на основе построения линейных трендов методом наименьших квадратов. Значимость полученных коэффициентов линейного тренда определялась по критерию Стьюдента [2] на 5\%-ном уровне значимости.

Проведенный анализ показал, что статистически достоверные тенденции смещения календарных дат в сторону более ранних характерны для всех характеристик динамики снежного покрова (табл. 3). За последний 30-летний период даты основных динамических характеристик смещаются по тренду на 5-6 дней на более ранние сроки каждые 10 лет.

Таблииа 3

Коэффициенты линейного тренда вида $y=b_{0}+b_{1} x$ календарных дат динамики снежного покрова на ст. Саратов ЮВ за 1975-2005 гг.

\begin{tabular}{|l|c|c|c|}
\hline \multicolumn{1}{|c|}{ Характеристики снежного покрова } & $\begin{array}{c}\text { Коэффициент } \\
b_{1}, \text { день/год }\end{array}$ & $\begin{array}{c}\text { Рассчитанный } \\
\text { критерий Стьюдента }\end{array}$ & $\begin{array}{c}\text { Значимость } \\
\text { коэффициента } \mathrm{b}_{1}\end{array}$ \\
\hline Дата появления снежного покрова & $-0,58$ & $-3,02$ & + \\
\hline $\begin{array}{l}\text { Дата образования устойчивого снежного } \\
\text { покрова }\end{array}$ & $-0,63$ & $-3,59$ & + \\
\hline Дата разрушения снежного покрова & $-0,52$ & $-4,04$ & + \\
\hline Дата полного схода снежного покрова & $-0,60$ & $-3,08$ & + \\
\hline $\begin{array}{l}\text { Продолжительность залегания устойчи- } \\
\text { вого снежного покрова }\end{array}$ & $-0,60$ & $-2,80$ & + \\
\hline
\end{tabular}

Примечание. Знак «+» - коэффициент $b_{1}$ статистически значим.

Для выявления характера эволюции высоты снегового покрова в последний 30-летний период нами был построен график изменения средних и максимальных за зиму высот снежного покрова от года к году с указанием линии тренда (рис. 1). Согласно полученной графи-

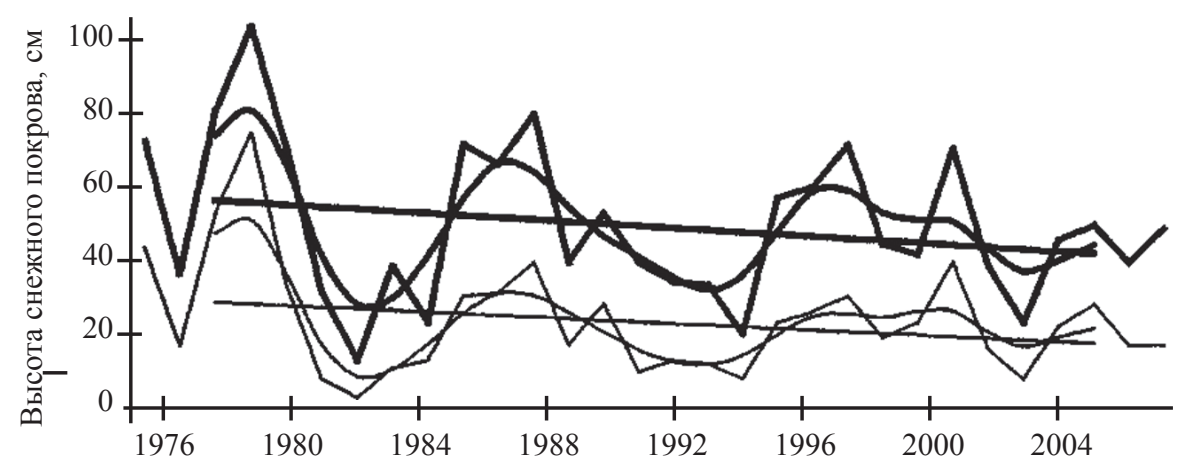

Рис. 1. Динамика максимальной и средней за зиму высоты снежного покрова на м/с Саратов ЮВ за 1976-2005 гг. 
ческой корреляции в данный период от года к году наблюдается уменьшение как максимальной, так и средней высоты снежного покрова. При этом уравнение тренда для максимальной высоты снегового покрова выглядит следующим образом: Нмакс. $=56,96-0,56 N$, а для средней за зиму высоты: Нсред. $=29,89-0,44 N$, где $N$ - порядковый номер зимнего периода в ряду наблюдений за последнее тридцатилетие. Следует заметить, что скорость уменьшения максимальной высоты несколько больше $(5,6 \mathrm{~cm}$ за 10 лет), чем средней за зиму высоты снежного покрова (4,4 см за 10 лет).

\section{Промерзание почвы}

Для исследования динамики промерзания почвы использованы наблюдения на метеорологической станции Саратов ЮВ с 1981 по 2003 год. В среднем глубина промерзания почвы нарастает к концу февраля до 65 см, а затем постепенно уменьшается и в первой декаде апреля происходит полное оттаивание почвы. Максимальная глубина промерзания за рассматриваемый период составила 148 см в марте 1982 года.

Многолетняя изменчивость глубины промерзания почвы рассматривалась на основе рассчитанных уравнений трендов:

для максимальных глубин:

$$
H=95,3-2,15 N,
$$

для глубин промерзания в 3-й декаде февраля:

$$
H=91,4-2,82 \mathrm{~N},
$$

где $H$ - глубина промерзания почвы, см; $N$ - порядковый номер зимнего периода в ряду наблюдений, когда $N=1$ для зимы 1981-1982 гг.

Из уравнения тренда (1) следует, что за период с 1981 по 2003 г. отмечалось уменьшение максимальной глубины промерзания почвы на 2,1 см в год. А за весь период в 22 года эта глубина уменьшилась по тренду на 46 см (рис. 2).

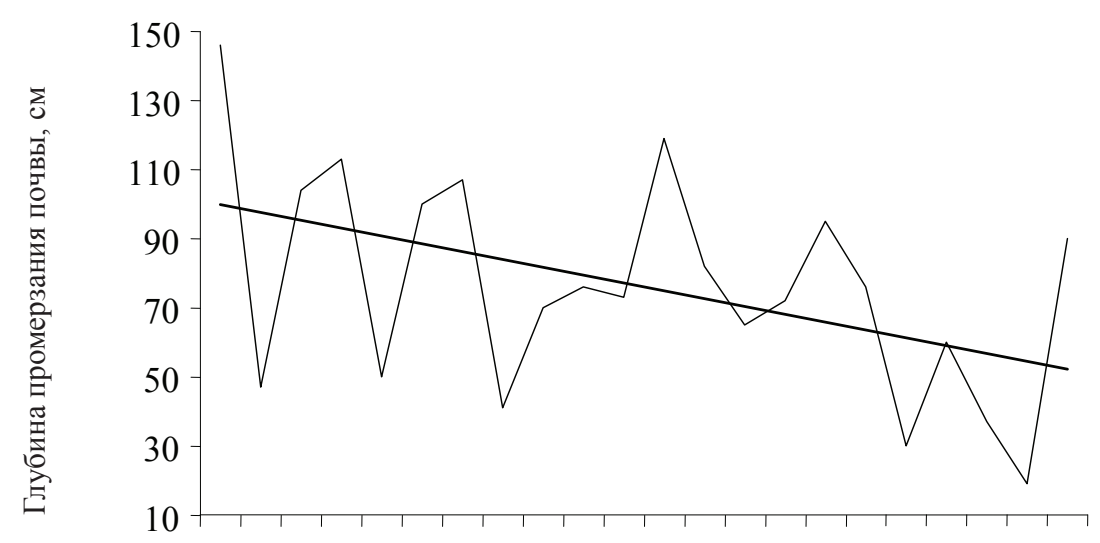

19821984198619881990199219941996199820002002

Рис. 2. Динамика максимальной глубины промерзания почвы на ст. Саратов ЮВ

В среднем наиболее глубоко почва промерзает в третьей декаде февраля. Как и следовало ожидать, характер изменчивости глубины промерзания в феврале аналогичен изменению максимальных глубин. В среднем за период скорость уменьшения толщины мерзлой почвы в конце февраля даже несколько больше максимальных значений за зиму и составляет 2,8 см в год. Коэффициенты линейного тренда для обоих уравнений статистически достоверны.

Самая ранняя дата начала промерзания почвы в Саратове в рассматриваемый период отмечалась 23 октября 1987 г., а самая поздняя - 12 декабря 1984 года. В среднем морозный период в почве устанавливается 21 ноября. Самая ранняя дата окончания промерзания почвы пришлась на 21 марта 1991 г., а самая поздняя - на 28 апреля 1995 года. В среднем почва оттаивает к 9 апреля.

Для оценки динамики календарных дат $(D)$ начала, прекращения промерзания почвы и про- должительности морозного периода (П) также рассчитаны линейные уравнения трендов: для даты начала промерзания почвы:

$$
D=25,4+0.39 N \text {, }
$$

для даты оттаивания почвы:

$$
D=24,9-0,19 N \text {, }
$$

для продолжительности (П) морозного периода в почве:

$$
\Pi=147,2-1,03 N,
$$

Продолжительность морозного периода в почве существенно сокращается. Из уравнений трендов следует, что начало промерзания почвы по тренду за 22 последних года сместилось на 9 дней на более поздние сроки, полное оттаивание почвы стало происходить на 4 дня раньше.

Продолжительность морозного периода в почве существенно сокращается. В соответствии с рассчитанным уравнением тренда (5) за исследуемый период продолжительность промерзания почвы в Саратове сократилась на 22 дня. 


\section{Выводы}

Исследование динамики снежного покрова и промерзания почвы по ряду наблюдений, проведенных на метеорологической площадке ст. Саратов ЮВ, свидетельствует, что с 1975 по 2005 г. произошло заметное сокращение как среднемесячных, так и экстремальных годовых отметок высоты снежного покрова. За последнее 30-летие самый первый, а также устойчивый снежный покров в среднем стали устанавливаться на 3-5 дней позже, чем в период с 1891 по 1980 год. Начало уменьшения снежного покрова стало происходить на 18 дней раньше, а полный сход снега - на 2 дня раньше, вследствие чего установилась тенденция уменьшения продолжительности залегания снежного покрова.

Исследование динамики промерзания почвы на метеорологической станции Саратов ЮВ в период с 1981 по 2003 г. показало, что глубина промерзания и продолжительность морозного периода в почве уменьшается.

Выявленные тенденции связаны с глобальным потеплением климата [3] и напрямую с повышением температуры воздуха в зимний период [4] в Саратове, которое особенно активно стало проявляться в 90-е годы. Повышение температуры воздуха, как минимальной, так и максимальной, особенно существенное за последнее 10-летие $[5,6]$, привело к общей тенденции уменьшения высоты снежного покрова, к сокращению срока его залегания, а также к уменьшению продолжительности промерзания почвы.

Приведенные в работе характеристики и тенденции их изменений следует учитывать при проектировании адаптивно-ландшафтных систем земледелия и разработке технологий возделывания озимых культур. Кроме того, полученные результаты могут быть использованы для метеорологического обеспечения строительной индустрии (укладки фундаментов, прокладки водопроводов и др. коммуникаций).

\section{Библиографический список}

1. Научно-прикладной справочник по климату СССР. Ч. 1-6, вып. 12. Л., 1988. 647 с. (Сер. 3. Многолетние данные).

2. Гмурман B.E. Теория вероятностей и математическая статистика. М., 2003. 479 с.

3. Kukla G., Karl T.R. Nighttime warming and the greenhouse enffect // Environ. Sci. Technol. 1993. Vol. 27, № 8. P. 1468-1474.

4. Скляров Ю.А., Иванова Г.Ф. Проблема глобального и регионального изменения климата // Изв. Сарат. ун-та. Новая серия. 2002. Т. 2, вып. 2. С. 44-48.

5. Левицкая Н.Г., Шаталова О.В. Современные тенденции изменения климата и их влияние на продуктивность сельскохозяйственных культур в Нижнем Поволжье // Проблемы и пути преодоления засухи в Поволжье: В 2 ч. Саратов, 2000. Ч. 2. С. 33-47.

6. Левиикая Н.Г., Шаталова О.В., Иванова Г.Ф. Оценка современных тенденций изменения климата и их последствий для сельскохозяйственного производства в Нижнем Поволжье // Повышение эффективности использования агробиоклиматического потенциала юго-восточной зоны России / ГНУ НИИСХ Юго-Востока Россельхозакадемии. Саратов, 2005. С. 273-284.

\section{ОПЫТ ЭСТЕТИЧЕСКОЙ ОЦЕНКИ ПРИВЛЕКАТЕЛЬНОСТИ РЕЛЬЕФА САРАТОВА}

\section{В.В. Копнина}

Саратовский государственный университет, кафедра геоморфологии и геоэкологии E-mail: kopnina@sgu.ru

В статье рассматриваются проблемы имеющихся методик по оценке эстетичности ландшафтов. Приведен опыт по оценке эстетической привлекательности рельефа на примере Саратова. Основами для оценки послужили понятия «морфологический ландшафт» и «морфологический пейзаж».

\section{Experience of an Aesthetic Estimation of Saratov's Relief Allure \\ V.V.Kopnina}

This article is devoted to problems of modern techniques of aesthetic landscapes objective appraisal. Such experience is shown according to example of Saratov. The base for an estimation are concepts «a morphological landscape» and «a morphological scenery».

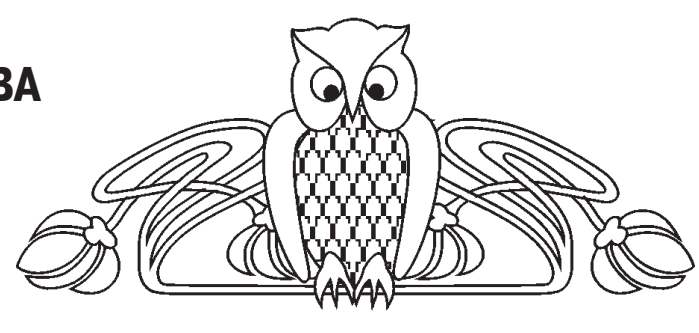

В формировании архитектурно-художественного облика города необходимо выявить природное своеобразие местности, остающееся, несмотря на возможные преобразования городских компонентов ландшафта.

В тех городах, где первоначальная подоснова отличалась выразительным рельефом, развитой гидрографической сетью или ценными насаждениями, эти черты сохраняются на века.

Рельеф земной поверхности является основной составляющей ландшафта. Вопросы эстетической оценки ландшафтов рассматриваются с разных позиций и имеют довольно много разработок в отечественной и зарубежной литературе. 